\title{
autêntica
}

\author{
ARTIGOS
}

\section{FORMAÇÃO DE PROFESSORES COMO OBJETO DE ESTUDO DA POLÍTICA EDUCACIONAL: CONTRIBUIÇÕES DA DEMOCRACIA DELIBERATIVA PARA UMA ANÁLISE DA META 15 DO PNE 2014-2024}

Jorge Atílio Iulianelli

\begin{abstract}
RESUMO: Este artigo discute a necessidade da abordagem da formação de docentes como objeto de estudo da política educacional. Parte-se do processo de aprovação do Plano Nacional de Educação (Lei 13.005/2014) que determina, em sua meta 15, providências necessárias à formação de professores. 0 foco é a discussão sobre o papel do regime de colaboração e da participação social na construção de estratégias de formação de professores. A primeira parte do argumento afirma que a história de formação de professores no país passou por muitos percalços, em especial em relação ao papel da colaboração entre os entes federados para tanto. Num segundo momento, observa-se como o debate parlamentar para a elaboração da meta 15 indica que a formação de professores necessita de uma política nacional, denotando o forte embaraço entre o papel da União e dos demais entes federados - como já percebido nas avaliações do Plano Nacional de Educação - PNE 2001-2010 - e na elaboração e efetivação do Plano de Desenvolvimento da Escola (PDE). Finalmente, discute-se como o regime de colaboração apresenta demandas de participação da comunidade escolar, da sociedade civil, em processos de gestão do ambiente escolar. O artigo oferece algumas conclusões heurísticas para o estudo do objeto em pauta.
\end{abstract}

PALAVRAS-CHAVE: Formação de professores, PNE 2014-2024, Meta 15, Democracia Deliberativa

\begin{abstract}
This article discusses the need to approach teacher training as an object of educational policy study. Part of the process of approval of the National Education Plan (Law 13,005 / 2014), which determines, in its goal 15, necessary measures for the training of teachers. The focus is the discussion about the role of the collaboration regime and social participation in the construction of teacher training strategies. The first part of the argument states that the history of teacher training in the country has gone through many setbacks, especially in relation to the role of collaboration between the federated entities. Secondly, the parliamentary debate for the elaboration of the goal 15 indicates that teacher training needs a national policy, denoting the strong embarrassment between the role of the Union and the other federated entities - as already National Education Plan - PNE 2001-2010 - and in the preparation and implementation of the School Development Plan (PDE). Finally, it is discussed how the collaboration regime presents demands for participation of the school community, civil society, in processes of management of the school environment. The article offers some heuristic conclusions for the study of the object in question.
\end{abstract}

KEY WORDS: Teacher training, PNE 2014-2024, Goal 15, Deliberative Democracy 


\section{INTRODUÇÃO}

O empenho dos educadores na defesa da escola pública, gratuita, obrigatória e de qualidade, tem marcado os movimentos de educadores no Brasil há décadas. A questão de qual educador para qual sistema escolar permanece aberta. Há um efetivo problema de descontinuidade entre as diferentes políticas educacionais exaradas pelo Estado brasileiro, a formação de docentes e as práticas docentes. Além disso, existe profunda descontinuidade da política de formação de professores neste país: não houve, propriamente, para não nos alongarmos desde a Colônia, desde a implantação dos cursos de Pedagogia, na década de 1930, um projeto de formação de professores e de profissionais da educação como tal que tivesse continuidade. Os efeitos dessa mixórdia refletem-se na fragilidade dessa formação e repercutem na fragilidade do projeto de País e de democracia que instauramos. Especificamente, com relação à educação básica, temos uma deficiência, seja na capacidade de permanência de docentes formados nas áreas em que lecionam, seja na capacidade de docentes em lidar com o processo formativo da cognição de nossas crianças e adolescentes - para tomar dois saberes docentes bastante descurados.

Os cursos de formação de professores oscilam entre o século XIX e o início dos anos de 1900 em experiências de origem francesa e alemã, sem continuidades. Apenas na década de 1930 foram iniciados no país os cursos de Pedagogia, reforçados pelo movimento dos Pioneiros da Educação Nova. Quando se fala em formação de professores, pelo menos três dimensões podem ser articuladas, aceitando sugestão de Severino (2004). A dimensão institucional diz respeito às condições de vida e de trabalho a que são submetidos os docentes, ao fluxo dos recursos e às políticas de gestão da profissão. Pode-se, também, destacar a dimensão pedagógica relativa à formação de docentes para atuação numa determinada prática. Aqui temos o debate sobre a existência de um modelo de formação centrado nos conteúdos cognitivos a serem desenvolvidos por meio da prática docente e de outro modelo, centrado nas práticas didáticas, ambos capazes de tornar a docência mais eficiente e eficaz. Nos dois modelos, a questão da finalidade da docência está em aberto e em construção. Uma terceira e última dimensão diz respeito ao caráter ético-político da formação docente, considerando-se essa formação como parte do processo de produção e reprodução de processos democráticos, participativos e promotores da cidadania.

O formato de curso que tem sido mais amplamente adotado combina a formação de professores para os anos iniciais da educação básica, em escolas normais de ensino médio e em cursos de graduação em Pedagogia. A formação de professores para a segunda etapa da educação básica e para o ensino médio é oferecida por meio das licenciaturas em áreas específicas, para as quais a formação pedagógica quase invariavelmente segue, ainda, apesar das variantes recentes, a distribuição $3+1$. No modelo $3+1$, que havia regularmente no passado, apenas um ano do curso era dedicado à formação pedagógica; agora, os 25\% de formação didático-pedagógica estão dispersos na formação dos futuros licenciados. Os processos de formação continuada de profissionais da educação são ainda mais tímidos e recentes.

A formação de professores é uma questão política. A maioria dos Estados-nação capitalistas optou por reger o processo de formação desses profissionais a partir do Estado, que define que competências, habilidades, capacidades devem ter esses profissionais e quais são os critérios que configuram a "boa" formação dos profissionais da educação. Gatti (2009, p. 12) indica que os investimentos educacionais no Brasil, entre os anos de 1960-2008, tiveram como resultado um "crescimento vertiginoso" das redes pública e privada de ensino fundamental. A demografia educacional indica a necessidade imperiosa de processos de formação de professores, e muitos deles, segundo a autora, ocorreram de forma improvisada. A formação de professores tem que lidar com as transformações sociais por que passam sociedades como a brasileira e a comunidade 


\section{autêntica}

internacional, como um todo, incluindo as questões referentes aos desafios socioambientais. De certa forma, ainda faz sentido a observação do que Saviani chama de "paradoxo pedagógico" para os cursos de formação de professores, que se estende desde o século XIX até os dias atuais. Por um lado, o modelo dos conteúdos culturais e cognitivos de formação de professores; por outro, o modelo pedagógico-didático. Seria, no dizer de Saviani, a oposição entre pedagogia tradicional e renovada (SAVIANI, 2011).

Gatti observa uma disjuntiva nas concepções do papel dos profissionais da educação: há os que entendem que eles deveriam ser formados para "a construção de uma sociedade justa na distribuição de seus bens e na preservação de valores de solidariedade e de coesão social" e aqueles que compreendem ser os profissionais da educação habilitados à "eficiência interna dos processos educativos e com a eficácia para preparar o aluno para participar das transformações em curso no mundo contemporâneo" (Gatti, 2009, p.12). Nenhuma dessas duas visões pode, no entanto, independer, segundo a autora, dos processos de valorização profissional, condições de vida e trabalho e do reconhecimento social necessário ao exercício responsável da profissão. Podemos, também, assumir que essas visões não necessitam ser excludentes.

Nosso interesse, neste artigo, é compreender a formulação do atual plano nacional da educação, identificando que modelo de docente está insinuado pelas suas metas e estratégias e se elas são uma resposta que inclui todos os concernidos, sendo o melhor argumento possível para a solução dos problemas desse campo específico. O propósito deste trabalho é notar contribuições que a perspectiva de democracia deliberativa oferece para uma abordagem teórica da política educacional, observando como seu objeto a formação de professores. Assim, considerando o caso brasileiro, em especial a partir das prescrições do atual PNE 20142024, analisam-se os propósitos, sobretudo, da Meta 15, que se referem especificamente à formação de professores. A estratégia argumentativa prevê os seguintes enfoques: 1. a formação de professores à luz do PNE 2014-2024 (BRASIL, 2015) e do PDE (BRASIL, 2007), na qual se conclui da dificuldade de extrair de planos resultados efetivos; 2. o processo de elaboração e os conteúdos do PNE 2014-2024, identificando elementos gerais referentes à formação de professores; 3 . o regime de colaboração como sendo - ou não - um eixo relevante para a efetividade de processos de formação de professores.

\section{O PNE 2001-2010 E O PDE: ALGUNS DESAFIOS RELATIVOS À FORMAÇÃO DE PROFESSORES}

Um dos meios pelos quais se tem buscado enfrentar os dilemas e impasses que cercam os processos de formação de professores é a elaboração dos planos decenais de educação. Conquanto desde os Pioneiros da Educação Nova existisse a pretensão de se haver no País um plano de educação, ela só se concretizou em 2001, quando da aprovação do Plano Nacional de Educação (PNE) 2001-2010 (BRASIL, 2001). A avaliação desse documento leva a constatar que houve muitas intenções e baixa capacidade de efetivação. Na verdade, o plano carecia de muita organicidade. Assim o é, que houve a necessidade de criar instrumentos intermediários como o Plano de Desenvolvimento da Educação, que foi mais um indicativo da ausência de uma política nacional de educação - note-se que emergiram, entre 1990-2009, várias políticas nacionais especiais de educação, para educação infantil, ambiental, indígena, da saúde etc. Apesar do Plano, e do esforço que ele representou, a visão fragmentada da educação e da formação dos profissionais da educação tem prevalecido, não apenas porque níveis, etapas e modalidades não são considerados como etapas de um processo, mas também porque os procedimentos, planos, políticas e diretrizes não estão de fato integrados em um regime de colaboração dos entes federados.

Foi uma conquista da sociedade civil a implantação de planos decenais da educação pelo Estado brasileiro. Desde a Lei de Diretrizes e Bases da Educação Nacional, LDBEN, Lei 9694/96 (BRASIL, 1996), foram 
aprovados dois planos nacionais de educação e um plano de desenvolvimento da educação que ficou como um interregno entre ambos. Conquanto a elaboração dos planos decenais esteja apoiada na legislação nacional e que haja aprovação de um PNE, como lei, esses documentos resultam num "poder fático", como lembra Brzinsky, dada a distância entre a legislação e a prática educacional observada neste país. Por isso, para entender como o PNE 2014-2024 nasce e cuida do tema da formação de professores, é recomendável lançar alguns olhares sobre elementos antecedentes. Tomemos uma avaliação do PNE 2000-2010 como elemento de análise. Para o que segue, orientamo-nos pelas reflexões propostas por Aguiar (2010).

O PNE 2001-2010 foi apresentado à sociedade brasileira por meio de uma emenda, com o apoio de setenta parlamentares. Sua aprovação deu-se dois anos após sua apresentação, por um substitutivo do relator, recebendo 158 emendas. Estava estruturado em três eixos: 1. educação como direito subjetivo individual; 2. educação como fator de desenvolvimento econômico e social; 3.educação para o combate à pobreza. Eram ainda tempos neoliberais. A Anped criticava, por exemplo, que, em nome do princípio federativo, aquele plano enfatizava o papel de municípios e estados, omitindo a responsabilidade da União na sustentação do regime de colaboração. Entre 2000 e 2004, a União não apoiou, como deveria, para que o plano se transformasse numa política de governo, e se tornasse uma política de Estado. A partir de 2004, entretanto, o Inep passa a disponibilizar alguns serviços fundamentais aos estados e municípios, procedendo a um diagnóstico da situação da educação no País, por região geográfica. Porém, ainda assim, a implementação do PNE estava comprometida.

O PNE entendia a educação como direito de cidadania e suas metas refletiam isso. Havia medidas voltadas para a formação de professores, que visavam à formação em nível médio, ao menos, em cinco anos, e à formação em nível superior, em dez anos. Em relação à graduação em nível superior, o PNE propunha-se a atingir 30\% dos jovens em faixa etária para esse nível de ensino em uma década. Porém, foi vetada a perspectiva de ter $40 \%$ dessas vagas atendidas pelas Instituições de Ensino Superior (IES) públicas. O diagnóstico elaborado pelo Inep identificava que o Estado brasileiro precisaria expandir, muito, a oferta de acesso à educação infantil e superior para atingir as metas que o plano propunha.

Efetivamente, o regime de colaboração foi uma das grandes dificuldades de implantação do PNE 2001-2010. De certa maneira, podemos dizer que o marco regulatório operou, sobretudo, com a perspectiva avaliativa do sistema, focando os resultados e usando os parâmetros dos indicadores internacionais. Não há dúvida de que a elevação da oferta tem que ser acompanhada por critérios de avaliação da qualidade da educação. Porém, o tema da qualidade é extremamente espinhoso. Para Aguiar (2010), as dificuldades de cumprimento das metas ocorreram mais pelo desafio do regime de colaboração que por dificuldades operacionais da União.

Isso não acompanhou um processo de definição de algum modelo de formação de professores, ou mesmo da criação de modelos consistentes de formação de professores. Houve, diacronicamente, a proposição do fim da formação de professores por meio do Ensino Médio - os cursos Normais deveriam ser extintos em 2006. Na sequência, porém, houve o restabelecimento dessa modalidade de formação e a expansão de redes de formação de professores por meio dos cursos de graduação em Pedagogia, sobretudo oferecidos por IES privadas, em especial para a formação inicial. E muitas formas de formação continuada para professores foram criadas, assim como formação inicial por meio da Educação a Distância.

Em 2007, o Ministro Hadad lançou, na 30ª reunião da Anped, o Plano de Desenvolvimento da Educação, o que sugeria empenho em atender a anseios da sociedade civil em relação aos percalços da educação. O PDE recebia, até então, na imprensa e na sociedade, a insígnia de beneficiar o empresariado educacional, descurando questões relevantes para uma política pública de educação para o País. No entanto, o lançamento na 


\section{autêntica}

Anped indicava, suspostamente, o empenho em tornar a transferência de recursos algo viabilizado diretamente para as unidades escolares, cortando a intermediação das redes distrital, estaduais e municipais. O PDE, por outro lado, nada mencionava sobre o veto dos presidentes Fernando Henrique Cardoso e Luís Inácio Lula da Silva ao investimento de $7 \%$ do PIB em educação. Previa, no entanto, o aporte de 0,7\% do PIB em educação básica - um atraso de dez anos. O documento apresenta o uso de indicadores de avaliação, como o Índice de Desenvolvimento da Educação Básica (Ideb), que era proposta do movimento Todos pela Educação, com forte participação do interesse privado, como mecanismo para aprimorar a qualidade da educação. Reforça, ainda, a noção do papel dos gestores municipais, sem praticamente mencionar os Estados, o que mostra uma compreensão, pelo menos, complicada, sobre o regime de colaboração. Identifica no Plano de Ações Articuladas (PAR), que deveria ser estruturado nos municípios, um instrumento de política de Estado, sem ter oscilação pelas trocas governamentais. Porém, como se construiria essa colaboração governamental? Eis uma questão que estava e continua em aberto.

Segundo Schneider, Nardi e Duli (2012), o que houve com o PDE, em relação à formação de professores, foi uma transferência de responsabilidade da União para os municípios. O PAR deve indicar o que o gestor municipal necessita para formação de professores. Ou seja, é o município que passa a ter a responsabilidade de buscar essa formação para seus quadros, e não a União, em regular e avaliar a oferta para atender a essa demanda, ou mesmo, criar os mecanismos objetivos para esse compromisso. No entanto, o MEC criou um manual para a elaboração do PAR. Nele se delimitam cinco áreas que o município deve cumprir para a formação de professores e se estabelecem indicadores para avaliação dessa ação dos municípios. O MEC passa a disponibilizar consultores para os municípios, com o fito de aqueles entes federativos elaborarem seus planos de ação, para o atendimento das metas. Embora o artigo mencionado seja sobre a situação de municípios do oeste catarinense, há elementos suficientes para arriscar uma generalização, sobretudo no seguinte ponto: a União oferece um modelo de diagnóstico e de formação, porém o resultado do processo de formação de professores fica sob a responsabilidade do município. Então, pode-se questionar com as autoras, quais as condições dos municípios de se submeterem às regulamentações propostas pela União?

\section{O PNE 2014-2024 E A FORMAÇÃO DE PROFESSORES}

Como se pode deduzir do arrazoado acima, a política educacional é uma questão delicada e disputada no cenário nacional. Os diferentes atores sociais empreendem uma peleja entre o público e o privado, entre uma visão patrimonialista do Estado e uma visão social do Estado, entre uma concepção da educação como um direito humano fundamental e educação como mercadoria - para abordar alguns dentre os muitos confrontos. Efetivamente, a construção do PNE 2014-2024 mostra, mais uma vez, como as disputas políticas protelaram as deliberações e podem relegar as efetivações previstas legalmente. Com efeito, entre 1996 e o primeiro plano, houve quatro anos de debates. E esse, segundo, teve a mesma sina. Não obstante, ambos os planos se expressam como leis para a regulação da educação no país.

Fez-se, acima, menção a alguma avaliação do PNE 2001-2010. O plano teria se tornado uma mera carta de intenções. Sua baixa efetividade foi tão intensa que se teve que elaborar um Plano do Desenvolvimento da Educação - sobre o qual recaíram críticas em relação ao seu erro de diagnóstico e à sua falta de apontamento de continuidade, dentre outras. De todos os modos, os planos anteriores expressavam de forma menor a participação social em sua elaboração. Não obstante, o Plano atual traz em seu bojo um dos mais relevantes desafios permanentes da educação brasileira, a saber: a coordenação do pacto federativo, ou, em outras palavras, a necessidade de maior clareza sobre o significado do regime de colaboração - bem como a necessidade de sua regulamentação. 
O atual PNE foi promulgado aos 24 de junho de 2015, pela Presidenta da República, por meio da Lei 13005/2014. Possui vinte metas e 253 estratégias. Por meio delas, articulam-se diferentes propostas de ações para que o país possa superar alguns de seus gargalos educacionais. Não é objeto deste artigo uma análise da integralidade do Plano. No entanto, para compreendê-lo, podemos aglutinar as estratégias em cinco eixos, seguindo a própria apresentação proposta pelo MEC:, 1. medidas estruturantes para educação básica de qualidade $(1,2,3,5,6,7,9,10,11)$; 2. redução das desigualdades e valorização da diversidade (4 e 8); 3. valorização dos profissionais da educação (15, 16, 17 e 18); 4. medidas para aprimorar as relações entre o ensino superior, a educação básica e a produção de conhecimento inovador (12, 13, 14); 5. medidas para fortalecer a gestão (19 e 20).

O Plano é uma proposta de reformulação de práticas que têm sido contestadas pela comunidade dos educadores e de proposição de novas práticas. As discussões sobre sua implementação permanecerão ao longo da década. De qualquer modo, várias medidas serão construídas ainda no primeiro ano de vigência da Lei. Os governos estaduais e municipais devem harmonizar seus planos ao plano nacional. Para isso, necessitam formar uma coordenadoria, elaborar um diagnóstico da situação educacional, formular um documento base, realizar uma consulta pública da qual emergirá projeto de lei, que será encaminhado ao legislativo estadual, distrital e municipal para aprovação e posterior promulgação pelo Executivo.

Além desses planos, deverá ser elaborado e implementado o Sistema Nacional de Educação, que, sonhado desde os Pioneiros da Educação, até hoje não conseguiu ter um modelo instalado. Sua elaboração dependerá de amplos debates que devem ocorrer até junho de 2015. O Sistema Nacional de Educação tem a difícil tarefa de construir unidade na diversidade, ancorado no pacto federativo.

Até hoje, como veremos adiante, o tema do regime de colaboração é um elemento distintivo e de difícil resolução na educação brasileira. Com o se sabe, a Constituição Federal de 1988, em seu art. 23, afirma que o regime de colaboração entre os quatro entes federativos, união, estados, distrito federal e municípios, é o meio pelo qual nossa diversidade encontra meios de se articular em unidade. Porém, como adverte o parágrafo único do mesmo artigo, esse regime precisa de regulamentação.

\subsection{META 15: SUAS ESTRATÉGIAS}

O processo que levou à formulação da Meta 15 não foi sem debates. Foram ao redor de três mil emendas apresentadas ao texto, inúmeras audiências públicas, duas emendas substitutivas, 155 destaques para votação e um complemento de voto aprovado, em 13 de junho de 2012, pela Comissão Especial da Câmara dos Deputados encarregada de sua análise, ressalvados os destaques (ABICALIL, 2014, p. 89).

Analisaremos, em distintas ocasiões, em relação à meta 15, a propositura de 189 emendas parlamentares da Câmara dos Deputados, que podem ser consultadas no site da Undime (Câmara dos Deputados, 2015). Enfocaremos apenas o texto relativo à meta 15, deixando para outra oportunidade a análise do debate parlamentar em torno de suas 13 estratégias.

Em relação ao texto da meta 15, ocorreram 26 proposituras de emendas, dentre as quais quatro substitutivas e 18 modificativas. O texto original, do PL 8035/2010, apresentado pelo Poder Executivo, assinado pelo então ministro da educação, Fernando Hadad, apresentava o seguinte teor:

Meta 15: Garantir, em regime de colaboração entre a União, os Estados, o Distrito Federal e os Municípios, que todos os professores da educação básica possuam formação específica de nível superior, obtida em curso de licenciatura na área de conhecimento em que atuam. 


\section{autêntica}

Ao fim do processo de votação das emendas, que durou quatro anos, circulação em todo o Congresso, interferências da sociedade civil e dos especialistas, a redação ficou assim:

Meta 15: Garantir, em regime de colaboração entre a União, os Estados, o Distrito Federal e os Municípios, no prazo de 1 ano de vigência deste PNE, política nacional de formação dos profissionais da educação de que tratam os incisos I, II e III do caput do art. 61 da Lei n 9.394, de 20 de dezembro de 1996, assegurado que todos os professores e as professoras da educação básica possuam formação específica de nível superior, obtida em curso de licenciatura na área de conhecimento em que atuam.

Nos dois textos está mantida a necessidade do regime de colaboração dos entes federados. A formação específica, em nível de ensino superior, para todas as professoras e professores da educação básica, incluindo a licenciatura específica da área de atuação, também foi assegurada. A inclusão refere-se à elaboração de uma política nacional de formação dos profissionais da educação, como preconizada pelo art. 61, da LDB que teve sua redação modificada pela Lei 12009/2014 (BRASIL, 2014). Nela destaca-se a relação entre teoria e prática no processo formativo e a valorização da experiência vivenciada anteriormente à formação, pelos profissionais da educação. O caput da meta estabelece o prazo de um ano de vigência do PNE, ou seja, até 25 de junho de 2015, o plano nacional de formação dos profissionais da educação deve estar elaborado.

A referência aos artigos da LDB, que dizem respeito à formação de professores, foi objeto de uma proposta substitutiva apenas, do Dep. Stepan Nercesian, do RJ, que mencionava dois dos três artigos, os de número 61 e 62 - excluía o art. 67, que aborda a valorização profissional. A emenda tinha preocupação mais exclusiva com a formação dos professores dos anos finais do ensino fundamental e do ensino médio, ou seja, preocupava-se com as licenciaturas. Houve, ainda, três outras emendas substitutivas que não foram agregadas ao texto do caput da Meta 15. Uma dizia respeito à valorização profissional e ao piso salarial; outra era referente à atribuição de responsabilidade com a formação dos profissionais da educação às IES comunitárias, além das públicas; outra uma terceira emenda propunha que $80 \%$ dos docentes tivessem a formação em nível superior, nas áreas correspondentes, durante o ano de 2015.

Das 18 emendas modificativas, 11 faziam referência aos $80 \%$ graduados em cursos de licenciatura, 4 pleiteavam o tento até 2015; 5, até 2016; e 2, até o quinto ano da vigência do plano. Houve quem reduzisse a expectativa para $70 \%$ até 2016. Essa controvérsia em torno da questão quantitativa não logrou êxito para o texto do caput. Buscou-se reverter a obrigatoriedade do ensino superior como formação dos profissionais de toda a educação básica; havia uma emenda modificativa que previa a formação dos profissionais da educação das séries iniciais por meio da instrução do ensino médio, como formação mínima - note bem, não menciona se essa formação deveria ser em Escola Normal. As outras emendas se concentravam em questões relativas à motivação para a carreira docente, além de chamar atenção para a colaboração responsável entre o setor público e privado no desempenho da tarefa formativa; também se chamava atenção sobre a valorização profissional. Tanto as emendas substitutivas como as modificativas afirmavam a necessidade do regime de colaboração entre os entes federados.

A meta tem um foco centrado na formação acadêmica dos profissionais da educação, em geral, e do docente, em particular. É reconhecido que o acesso à educação universitária não atendeu a todos que exercem a docência na educação básica. Várias medidas têm sido tomadas para suprir essa deficiência. Atingir uma meta como essa exige intensa cooperação entre os entes federativos. Isso nos coloca a indagação, anunciada acima, de como esse regime de colaboração pode atender, da melhor forma possível, essa exigência. Essa reflexão atém-se a uma questão mais ético-político do técnica ou apenas administrativa. 
Podemos agrupar as vinte estratégias da emenda em três grupos. O primeiro grupo refere-se às bases estatais e de financiamento da formação docente $(15.1,15.2)$. O segundo indica como deve ser o procedimento para a formação das diferentes capacidades docentes, para os diferentes níveis e modalidades de ensino. Embora haja ênfase na educação básica, considera-se, ainda, a educação profissional, o ensino de línguas, a formação específica para as populações tradicionais (15.3, 15.4, 15.5, 15.8, 15.9, 15.10, 15.11, 15.12 e 15.13). Finalmente, podemos agrupar aquelas estratégias que correspondem à regulação dos cursos superiores de formação de docentes, também promovendo a renovação curricular $(15.6,15.7)$. Podemos fazer a ilação de ser o regime de colaboração tema central relativo à formação de professores nesse atual PNE.

\section{REGIME DE COLABORAÇÃO: ENTRE O CONTRATUALISMO E A DEMOCRACIA DELIBERATIVA: BREVE DIGRESSÃO}

Se o regime de colaboração expressar uma estratégia jusfilosófica contratualista liberal, a ênfase recai sobre o papel do indivíduo, suas liberdades fundamentais; no escopo republicano, por sua vez, destacar-se-ia a função dos entes federados em fazer valer os valores comunitários, o Estado de direito. O que isso significaria? Seria a valorização da formação, a partir da manutenção da tensão público versus privada, na qual as Instituições de Ensino Superior (IES) públicas, federais e estaduais, formam o "excelente" e as IES privadas, o "regular" e o "deficiente" profissional da educação? Seria a valorização da formação algo acelerado para cumprir a meta proposta, envolvendo todas as formas de cooperação possível - pública, privada, Educação a Distância - tendo em vista que faltam apenas completar 25,2\% dos professores da educação básica com formação em nível superior e 68,2\% com as licenciaturas na área em que atuam?

Se o regime de colaboração expressar uma estratégia jusfilosófica da democracia deliberativa, por outro lado, o que significaria? Maior consulta aos especialistas da área para identificar os mecanismos sociais para o cumprimento da meta? Maior consulta aos profissionais da educação para identificar os mecanismos sociais para o cumprimento da meta? Elaboração de consultas, referendos, conferências, para a efetivação da meta?

Tomemos como hipótese a argumentação da proposta habermasiana de democracia deliberativa (HABERMAS, 1999), para analisar o modelo de regime de colaboração. Necessariamente, esse regime deveria conter formas de participação direta da cidadania, atualmente pouco evidentes nas propostas legais. Na verdade, a comunidade escolar, e mesmo o conjunto dos interessados nos destinos da educação, exceto os operadores do mercado educacional, não tem mecanismos de participação assegurados legítima e legalmente. Se a efetivação do PAR dialogasse, por exemplo, com o Estatuto da Cidade (Lei 10257/2001), deveria haver instrumentos de debates, audiências e consultas públicas, que favoreceriam a participação direta da população na elaboração desses instrumentos, até mesmo na discussão sobre qual tipo de formação de professores a sociedade quer.

Habermas (2014, p. 100) chama atenção para o fato de a cidadania moderna implicar duplo aspecto. Por um lado, somos autolegisladores: por outro, cidadãos livres e portadores de direitos. A ideia de participação na constituição comum, por meio da vontade política, é, pois, expressão de nosso vínculo de inclusão e deliberação, por intermédio do Discurso. O que está em jogo? Para os liberais, as leis seriam legítimas apenas se adviessem de direitos humanos moralmente estabelecidos, e, então, o legislador democrático deveria se submeter a esses limites. Ou, então, para os republicanos, a legitimidade das leis adviria da vontade democrática, assim, o povo soberano poderia eleger normas, até mesmo contrárias ao Estado de direito, porque nada impediria isso. Essas duas versões contratualistas nos levariam a regimes de colaboração que não tratariam todos os envolvidos numa perspectiva imparcial e universal. 


\section{autêntica}

Por outro lado, se orientássemos a construção de um sistema de direitos a partir da perspectiva do Discurso, dos processos da democracia deliberativa, sairíamos desse impasse. Por essa perspectiva, admitiríamos a cooriginariedade da democracia e do Estado de direito. A necessidade das noções de mutualidade e a reciprocidade dos agentes discursivos envolvidos se impõe. Como afirma Habermas:

Pois, pressupondo que os sujeitos constituintes querem fundamentar deliberativamente uma associação voluntária [...] só podem tomar sua primeira decisão depois que se esclarecerem in abstracto a respeito de que espécies de liberdades subjetivas de ação eles precisam conceder-se mutuamente, antes de poder regular legitimamente uma matéria qualquer com os meios do direito moderno (HABERMAS, 2004, p. 101).

A imparcialidade impõe-se à busca comum para a solução de problemas, também, por meio do Discurso. A cidadania é um processo cooperativo em meio aos conflitos e desigualdades existentes na sociedade capitalista. O consenso não é abolição do dissenso ou do conflito; é a capacidade de superação de suas mazelas. Aliás, é por meio dessa capacidade interativa, intersubjetiva, que cada cidadão pode conciliar os modelos do Estado de direito com os do Estado de bem-estar social. Nesse ponto, seguramente, teríamos mais a refletir sobre contribuições para essa reflexão da lógica do bem-viver que o pensamento latino-americano tem tratado, porém não nos cabe aqui nesse momento senão aludi-lo. O que Habermas chama a atenção, entretanto, não é de menor importância para lidarmos com o tema do regime de colaboração, ao menos se consideramos a necessidade da maior participação cidadã possível para a elaboração de planos que tenham maior efetividade. Nesse ponto, podemos abandonar Habermas em favor de observações de Jamil Cury.

O Congresso até a presente data não regulou a questão do regime de colaboração. Diante disso, Cury (2014, p. 36) questiona: o que deve ser nacional, estadual, distrital e municipal na educação?; como distinguir as diferenças desses planos de intervenção?. Em 1988, quando da elaboração da Constituição Federal, havia um temor de perda de autonomia dos entes federados. O resultado disso, no entanto, foi indefinição de papéis, em especial no caso da educação. Se já existe um Plano Nacional de Educação, Fundeb e outras formas de colaboração entre os entes federados, Cury (2014, p. 41) pergunta: para que um Sistema Nacional de Educação?). Concordamos com o autor, não só com relação aos questionamentos feitos, quanto com a afirmação de que o problema está na construção da justiça educacional, no sentido de conferir as mesmas oportunidades e encetar ações que cooperem com a superação das desigualdades instaladas nos interstícios da vida nacional.

Cury chama atenção para o fato de que, do ponto de vista de nossos direitos básicos de cidadania, somos todos cidadãos brasileiros. Como brasileiros, temos direito a uma formação comum. Isso implica dispositivos, por exemplo, que regerão a quantidade de horas-aula necessárias para a formação de nossas crianças, jovens e adultos. Não é claro qual o melhor caminho, se um currículo centralizado, em nome da unidade federativa, ou um currículo que valorize as realidades da diversidade regional, em nome das diferenças culturais. Essas são questões que precisam de aprofundamento e debate para a construção de um Sistema Nacional de Educação.

Poderíamos nos questionar sobre os benefícios de um regime de colaboração mais ou menos centralizado. Em termos de resultados para a aprendizagem, medidos, por exemplo, pelo Programme for International Student Assessment (Pisa - Programa Internacional de Avaliação de Estudantes), que oferece uma base comparativa internacional de desempenho "cognitivo" dos estudantes, os estudos internacionais têm demonstrado que é mais eficiente o desempenho dos alunos em países nos quais há centralização da política educacional (AKKARI, 2013, p. 42). Porém, adverte Akkari, no estudo mencionado, seria inoportuno generalizar essa informação, haja vista a baixa quantidade de estudos sobre os efeitos da descentralização. O 
que se pode inferir dos estudos atuais, segundo o mesmo pesquisador, é que haveria, por meio de ações descentralizadoras da política nacional, maior propensão para a afirmação das desigualdades que para a coesão social. Ao que parece, um regime de colaboração centralizado poderia ser melhor para os resultados das ações educativas escolarizadas.

\title{
3.1. ANÁLISE DE ALGUMAS ESTRATÉGIAS PARA O CUMPRIMENTO DA META 15
}

A observação das emendas parlamentares relativas à meta proposta é bastante elucidativa. Inicialmente, o texto original continha na Meta 15 um total de 10 estratégias. O conjunto das emendas chegou a compor um total de 25 estratégias para a meta. O texto final possui 13 estratégias da meta. As metas que mais receberam emendas foram sobre formação continuada (15.11 recebeu 30 emendas); a referente a bolsas de estudo (15.12 recebeu 15 emendas); as referentes à iniciação à docência (15.3) e à formação docente para educação profissional (15.13), ambas recebendo 13 emendas cada uma. Como será discutido adiante, as emendas propostas em 15.11 diziam respeito, também, ao tema da formação continuada, o qual terminou sendo o hegemônico dessa estratégia.

Tomemos a estratégia 15.1, que aponta a necessidade do regime de colaboração. Diz o texto aprovado da meta:

\begin{abstract}
Atuar, conjuntamente, com base em plano estratégico que apresente diagnóstico das necessidades de formação de profissionais da Educação e da capacidade de atendimento, por parte de instituições públicas e comunitárias de Educação Superior existentes nos Estados, Distrito Federal e Municípios, e defina obrigações recíprocas entre os partícipes.
\end{abstract}

O texto apresentado ao Congresso possuía a seguinte formulação:

Atuar conjuntamente, com base em plano estratégico que apresente diagnóstico das necessidades de formação de profissionais do magistério e da capacidade de atendimento por parte de instituições públicas e comunitárias de educação superior existentes nos Estados, Municípios e Distrito Federal, e defina obrigações recíprocas entre os partícipes.

Há apenas uma alteração no texto aprovado: tratar de profissionais da educação e não de profissionais do magistério. Isso amplia a noção, dando conta de supervisores e gestores educacionais, dentre outros profissionais que estariam descurados. O foco central está em criar uma estratégia de formação desses profissionais em regime de colaboração entre Estados, Distrito Federal e Municípios. Note-se, a União não está mencionada nessa estratégia. Houve cinco emendas apresentadas sobre essa estratégia na Câmara. Elas indicavam: (a) a necessidade de uma diretriz curricular para a formação; (b) a necessidade de se criar um sistema nacional de formação desses profissionais; (c) a obrigação de se cumprir a Lei do Piso Salarial para a Educação Básica, (d) a modificativa para profissionais da educação. Os temas (b) e (c) foram tratados em outras estratégias. O tema (a) foi abordado nesse PNE por meio da indicação no caput da meta 15, ao mencionar-se a necessidade de uma política nacional de formação de profissionais da educação.

Essa estratégia, 15.1, pois, diz respeito diretamente a um aspecto político do regime de colaboração. Esses planos têm por prazo junho de 2015. Vários municípios, em abril de 2015, já possuem seus planos elaborados e aprovados pelas Câmaras, e, em alguns casos, até promulgados pelo Executivo. O processo de elaboração inclui a realização de consultas públicas. A previsão de participação é intensa. As consultas públicas dependem 


\section{autêntica}

da disponibilidade da informação para que o processo ocorra. Essa estratégia, como vimos, é parte da base estatal para que a vigência do PNE 2014-2024 seja mais que uma carta de intenções.

O texto aprovado da estratégia 15.11 foi o seguinte:

Implantar, no prazo de um ano de vigência desta Lei, política nacional de formação continuada para os profissionais da Educação de outros segmentos que não os do magistério, construída em regime de colaboração entre os entes federados.

A votação não tinha esse texto como base. O debate na Câmara levanta 30 emendas. O tema da formação continuada emerge e o reforço do regime de colaboração, também, com explicitação dos entes federados, que inclui a União. A formação continuada deve ser objeto de uma Política Nacional, que deve estar elaborada até 24 de junho de 2015. Nas emendas aparecem alguns questionamentos, como: a formação continuada deve ser presencial ou a distância?; deve lidar com a formação em direitos humanos, em temas de cultura afro-brasileira ou raça, etnia, gênero e orientação sexual? E segue. Não é o caso de registrar neste artigo o conjunto de debates propostos, embora ele necessite de avaliação futura. A construção de uma política nacional de formação de profissionais da Educação é parte, conforme observado, das ações de capacitação específica dos atores sociais da ação educativa, ingrediente essencial para aprimorar a aprendizagem de nossos estudantes, o fluxo e outras medidas que permitiriam avaliar como a ação educativa promove a formação de cidadãos trabalhadores, produtivos, críticos e felizes. 


\section{CONSIDERAÇÕES FINAIS}

Este estudo propõe uma aproximação com um tema candente, que dissemina muitas questões, tais como: qual o lugar da sociedade na formação de profissionais da educação?; deve a formação de profissionais da educação ser matéria exclusiva de especialistas?; como poderemos querer uma gestão democrática da educação se excluímos a comunidade escolar do debate sobre o conteúdo e a modalidade de formação?; para qual sociedade a ser formada?

O processo de participação social nesse debate está ainda por ser construído. Oxalá venham a existir condições para que, em relação à formação dos profissionais da educação, sejam construídas mediações que elaborem instrumentos para a participação social dos cidadãos na indicação, por exemplo, dos conteúdos éticos que devem normatizar a prática dos profissionais da educação, do papel da escola na mediação de conflitos sociais e, até mesmo, na solução de problemas comunitários.

O processo de participação social é necessário. Para que o Plano Nacional de Educação seja mais que uma carta de intenções, a sociedade brasileira precisa se apropriar dele. Como cidadãos, não apenas como comunidade escolar, precisamos empreender esforço social e coletivo para identificar quais ações políticas são necessárias desenvolver. Habermas, retomando Kant, fala da "associação da coerção recíproca universal com a liberdade de cada um". O direito é, ao mesmo tempo, fruto de nossa soberania e nos impele e compele à determinada ação, o que nos leva a agir mais por assentimento a normas que por temor a sanções. É nossa atitude ético-política que fundamenta o direito; as normas, para serem validadas, necessita de um assentimento ético por parte de quem é cidadão.

A formação de professores é um tema estratégico para as políticas educacionais. As últimas três décadas, no mundo, assistiram a forte incremento da demografia de estudantes, em especial da Educação Básica. Simultaneamente, isso demandou o aumento quantitativo dos profissionais da educação, em especial de professores. Segundo a Unesco, até 2015, vários países correm o risco de ficarem sem professores qualificados. O PNE 2014-2024 continua e aprimora medidas para que o Brasil não participe dessa estatística.

Quais são as tendências internacionais das políticas educacionais para formação de professores? Conforme Akkari (2013), são três. A primeira é a 'universitarização' da formação. A ideia básica é que a formação em nível superior tem suporte mais científico para a qualificação para o magistério. Uma crítica ao modelo é "a distância significativa entre a universidade e o âmbito escolar" (AKKARI, 2013, p. 110). Parece, porém, que essa tendência prossegue a se fortalecer. A segunda tendência refere-se a uma maior quantidade de tempo para a formação de professores, um "alongamento da duração da formação e aumento das qualificações exigidas para realizar a formação" (AKKARI, 2013, p. 111). A terceira tendência inclina-se para a multifacetação dos modelos formativos, valendo para a formação inicial, continuada e em exercício da função.

Efetivamente, essas tendências devem relacionar-se com a discussão sobre a profissionalização da profissão. Porém, evitaremos abordar esse tema nesta ocasião. Sabemos que, no Brasil, ainda persiste a perspectiva de desvalorização da profissão de professores, em especial da Educação Básica, os quais são tratados como se exercessem, conforme Akkari (2013, p. 114), uma 'profissãozinha' ou uma 'semiprofissão'. Efetivamente, a formação de professores é um elemento para a valorização profissional dos professores e isso precisa ser abordado na política educacional de um país. 


\section{autêntica}

Parece que processos como a aprovação e a implementação de planos educacionais, como parte da política educacional, dependem do reconhecimento de nossa condição intersubjetiva. Isso não é tarefa exclusiva do Estado; é também tarefa da sociedade. Processos políticos transformam-se em processos político-sociais por ampliação dos circuitos de informação, por deliberação conjunta e por participação efetiva. Nenhum processo nas sociedades capitalistas ocorre sem que os interesses contraditórios em disputa emerjam e circunstanciem as situações. O PNE 2014-2024 não é uma exceção. Nele, a formação de docentes é fundamental. A compreensão da política de formação de docentes como objeto de estudo da política educacional parece ser uma necessidade dos estudos do campo. A abordagem da democracia deliberativa pode ser uma chave de leitura consistente para nossas análises. 


\section{REFERÊNCIAS}

AGUIAR, Marcia Ângela. Avaliação do Plano Nacional de Educação 2001-2009: questões para reflexão. In: Educação e Sociedade., Campinas, v. 31, n. 112, p. 707-727, jul.-set. 2010. Disponível em: <http://www.scielo. br/pdf/es/v31n112/04>. Acesso em: 30 mar. 2014.

AKKARI, J. Internacionalização das políticas educacionais. RJ: Vozes, 2013.

BRASIL, Lei 13005, de 26 de junho de 2004, Estabelece o Plano Nacional de Educação 2014-2024. Disponível em: <http://www.planalto.gov.br/CCIVIL_03/_Ato2011-2014/2014/Lei/L13005.htm>. Acesso em: 30 mar. 2014.

BRASIL, Lei 10.172, de 9 de janeiro de 2001. Aprova o Plano Nacional de Educação e dá outras providências. Disponível em: <http://www.planalto.gov.br/ccivil_03/leis/leis_2001//10172.htm>. Acesso em: 30 mar. 2014.

CURY, Carlos Roberto Jamil. Sistema nacional de educação: uma reflexão provocativa ao debate In: GADOTTI, M. et al. (org.). O sistema nacional de educação: diversos olhares 80 anos após o Manifesto. DF: Unesco, 2014, p. 34-43.

HABERMAS, J. Direito e Democracia. Trad. Flavio Beno Siebeneichler. RJ: Tempo Brasileiro, 1999 (2 volumes).

HABERMAS, J. Na esteira da tecnocracia. SP: Unesp, 2014.

SAVIANI, Dermeval. Formação de professores no Brasil: dilemas e perspectivas. In: Poíesis Pedagógica, 9, n¹, jan./jun. 2011, p.07-19.

SCHNEIDER, M.P., NARDI, E.L., DURLI, Z. O PDE e as metas do PAR para a formação de professores da educação básica. In: Ensaio. Rio de Janeiro, v. 20, n. 75, abr./jun. 2012, p. 303-324.

SEVERINO, A. J. A formação e a prática do professor em face da crise atual dos paradigmas educacionais. In: Ciência \& Opinião, v. 1, n. 2/4, 2004, p. 15-31. 